\title{
Modelagem comportamental pela técnica da preferência declarada aplicada aos agricultores de Santa Helena (PR)*
}

\author{
Leoveraldo Curtarelli ${ }^{1}$ \\ Weimar Freire da Rocha Júnior ${ }^{2}$ \\ Pery Francisco Assis Shikida ${ }^{3}$
}

Resumo: Este trabalho trata do comportamento dos agricultores frente às opções de investir ou não em terras, de forma a modelar como estes tomam as decisões sobre seus investimentos, utilizando-se da Técnica da Preferência Declarada. A pesquisa centrou-se nos agricultores de Santa Helena (PR), proprietários de áreas iguais ou superiores a 30 (trinta) alqueires. A coleta dos dados baseou-se em entrevistas com uma amostra de 40 agricultores. Como principais resultados, os atributos mais significativos para o modelo foram: "finalidade do investimento"; "condições de pagamentos" e "capital". O grupo pesquisado apresenta-se propenso a realizar investimentos em terras devido a: segurança financeira; possibilidade de pagamento a prazo; e opção de utilizar capital próprio para honrar as obrigações.

Palavras-chave: Técnica da Preferência Declarada; Terras; Logit.

Classificação JEL: Q12 Q14

\footnotetext{
* Os autores são gratos aos pareceristas desta Revista pelas profícuas sugestões.

${ }^{1}$ Economista, Mestrando em Desenvolvimento Regional e Agronegócio pela Universidade Estadual do Oeste do Paraná - UNIOESTE-Toledo. Rua da Faculdade, 645. CEP: 85.903-000. Toledo, PR. E-mail: leoveraldo@yahoo.com.br ${ }^{2}$ Professor Adjunto do Curso de Economia e do Mestrado em Desenvolvimento Regional e Agronegócio da UNIOESTE-Toledo. Pesquisador do GEPEC. E-mail: wrocha@unioeste.br ${ }^{3}$ Professor Associado do Curso de Economia e do Mestrado em Desenvolvimento Regional e Agronegócio da UNIOESTE-Toledo. Bolsista de Produtividade em Pesquisa do CNPq e Pesquisador do GEPEC - E-mail: pfashiki@unioeste.br
} 
Abstract: This work analyses the behaviour of farmers as to the options of investing or not investing in buying lands, and aimed to know as farmers make their decisions on investments with use of the Technique of Declared Preference. The research based on farmers of Santa Helena (PR), proprietors of areas equal to or higher than 72 (seventy-two) hectares. Data collection was based on interviews with a sample of 40 farmers. As principal results, the most significant attributes for the model were: "purpose of the investment"; "conditions of payments" and "funds". Therefore, the investigated group presents a tendency to accomplish their investments in owning lands due to: financial security, possibilities to pay in instalments and option of using their own funds to cover the debt.

Key words: Technique of Declared Preference; Lands; Logit.

JEL Classification: Q12 Q14

\section{Introdução}

A integração comercial brasileira vem ocorrendo no contexto de uma nova ordem mundial caracterizada, principalmente, pela integração de países por meio de acordos bilaterais e multilaterais (zonas de livre comércio, uniões aduaneiras e mercados comuns).

Nesse dinâmico contexto, o Brasil elevou a dependência de produtos agrícolas como fonte de divisas, embora a demanda mundial por este tipo de produto tenha crescido menos vis-à-vis a demanda por produtos industrializados (CARVALHO e SILVA, 2005). Diante dessa situação dual a agricultura brasileira, de modo não homogêneo, procurou se modernizar visando acompanhar - numa condição competitiva - as vicissitudes do mercado.

Assim, a agricultura amiúde foi receptora de grande parcela dos investimentos no Brasil. As áreas de terra sempre foram atraentes, principalmente a partir do final da década de 1990, quando se formou um cenário favorável para a agricultura posto a elevação dos preços de importantes commodities agrícolas. Culturas, como a soja, impulsionaram os preços da terra drasticamente. Com efeito, conforme Braun (2004), os produtos destinados ao mercado externo foram os que apresentaram 
melhor desempenho no setor agrícola, enquanto que a agricultura de mercado interno teve um desempenho inferior.

De acordo com Bacha (2004), a avaliação da performance da agricultura brasileira, na década de 1990 pode ser feita comparando a evolução de seu produto com os demais setores de atividade. Apesar das altas adversidades, como a diminuição do crédito oficial, a abertura comercial e a recessão econômica, entre outros, a agricultura apresentou, ao longo dos anos 90, taxas de crescimento significativas superando, inclusive, a variação do PIB nacional, da indústria e do setor terciário.

Estudos que mostram a competitividade do agronegócio brasileiro (vide, por exemplo, VICENTE, 2005) ressaltam a importância de se investir no setor (mormente em máquinas, sementes, etc.), visando com isto maior capacitação. Mas, quais são as características consideradas pelos agricultores no momento de se decidirem por um tipo de investimento fundamental: o investimento em terra?

Neste trabalho optou-se por avaliar a categoria de agricultores de Santa Helena (PR), a respeito das prioridades nas suas decisões de investimentos. Conforme salientado, o cenário agrícola favorável da década de 1990 propiciou um maior desempenho da atividade agrícola, principalmente na produção de soja. Por isso, selecionou-se uma categoria que teria recursos financeiros suficientes para investir. A aquisição de terras como investimento é alternativa com risco inferior em relação ao, por exemplo, mercado financeiro, porém tem menos liquidez. Investimentos como ações, títulos, dólar, FII (fundos de investimento em imóveis) e outros demandam um maior conhecimento por parte do investidor, aumentando seu grau de risco e liquidez (sobre isto, ver: MELLAGI FILHO e ISHIKAWA, 2003). Supõe-se que o valor da terra seja menos volátil, no curto prazo, pelo fato de existirem informações mais transparentes e disponíveis, pois o preço da terra é estabelecido pelo mercado, geralmente, pela forma de equivalência com produtos.

Destarte, este trabalho pretende levantar as características consideradas pelos agricultores no momento de se decidirem por este tipo de investimento, configurando-se o comportamento do investidor, hipoteticamente, guiado por trade-offs, entre rentabilidade e risco.

Isto posto, além desta introdução, nas próximas seções apresentamse, na seqüência, a revisão de literatura, metodologia, e resultados e discussão. As considerações finais procuram sumariar este trabalho. 


\section{Revisão da literatura}

Esta revisão irá subdividir em duas partes: uma primeira que versa sobre o mercado de terras; e a segunda que enfoca preliminarmente a Técnica de Preferência Declarada (TPD).

Haja vista o Brasil ter elevado a dependência de produtos agrícolas como fonte de divisas, e após elevação do preço de importantes commodities agrícolas nos anos 90, o preço da terra mostrou sinais de crescimento, aparecendo preocupações quanto aos limites dessa evolução de preços, seja para o fator terra e/ou para o próprio preço dos produtos agrícolas (DIAS et al., 2001).

De acordo com Reydon (1992), o mercado de terras, seja para capital próprio ou ganhos especulativos, é consequiência das negociações efetuadas entre compradores e vendedores, em que normalmente o comprador tem expectativas mais elevadas sobre os ganhos futuros com a terra do que o seu vendedor. Não obstante, assim como outros setores da economia, a demanda por terras no mercado agrícola (e conseqüentemente seus preços) tende a se elevar durante o ciclo de crescimento do setor, ao revés, durante uma depressão e com incertezas reinantes, ocorre comumente a preferência pela não negociação (com queda dos preços).

Afora as questões conjunturais ora citadas, a busca pelo retorno do investimento (neste caso, investir ou não em terras) é um fator sempre presente numa negociação de ativos, daí ocorrer o tão desejado retorno irá depender de uma série de variáveis (KOPITTKE e CASAROTTO FILHO, 2000).

Isto posto, a questão premente neste trabalho é saber quais são as variáveis que influenciam o agricultor no momento da aquisição de terras, e aqui elencam os seguintes atributos (que se baseou em comportamentos típicos de um consumidor - sobre isto, ver: PINDYCK e RUBINFELD, 1994): perspectiva de lucro; segurança; renda; valor do investimento; condições de pagamento; capital utilizado na compra (se é próprio ou de terceiros); credibilidade do governo; perfil do investidor (conservador, moderado ou agressivo); estado civil; dimensão da área; e escolaridade.

Para saber dessas especificidades do agricultor no momento de aquisição de terras, esta pesquisa buscou um método apropriado para tal, qual seja, a Técnica de Preferência Declarada (TPD), que foi desenvolvida originalmente por pesquisadores de marketing, no início dos anos 70, 
com o objetivo de aprimorar conhecimentos sobre o comportamento dos clientes (usuários) (FREITAS, 1995).

Segundo Kroes e Sheldon (1988), a TPD refere-se a uma família de técnicas que utiliza o relato de indivíduos acerca de suas preferências em relação a um conjunto de opções pré-definidas para estimar funções de utilidade.

Os dados de Preferência Declarada (PD) possibilitam que seja estimado um modelo para cada entrevistado. Isto é possível uma vez que cada entrevistado fornece informações suficientes para que sejam identificados todos os parâmetros de interesse. Esta característica da abordagem de PD é interessante na prática da segmentação de mercado, porque permite ao analista identificar segmentos com preferências homogêneas (KROES e SHELDON, 1988).

Uma das principais características das pesquisas de PD é o fato dela lidar com a expectativa de comportamento dos entrevistados, ao invés do seu comportamento real. Isto ocorre porque os entrevistados são estimulados a demonstrarem suas preferências frente a cenários hipotéticos pré-definidos pelo pesquisador. Estes cenários colocam os entrevistados frente a informações sobre as implicações mais relevantes em relação às opções que são propostas com a intenção de não apenas criar ambientes realistas, mas também de explorar ao máximo os trade-offs associados às escolhas feitas. A aplicação de TPD tem por resultado a resposta com maior probabilidade de ocorrer (resposta potencial), dada uma situação que contenha uma determinada combinação de níveis de atributos em cada alternativa, ou cenário hipotético, conforme definido no projeto do experimento (SENNA e MICHEL, 2000).

De forma mais sintética pode-se dizer que a TPD é fundamentada em entrevistas nas quais se apresenta ao entrevistado cenários hipotéticos, para que seja escolhida a situação de interesse.

\section{Metodologia}

Para a aplicação da TPD será utilizada nesta pesquisa a análise Logit. ${ }^{4}$ Para LIZARRAGA (1996) a análise Logit é uma técnica de probabilidade

\footnotetext{
${ }^{4}$ Maiores considerações sobre a análise logit, ver, dentre outros: Hoffmann e Vieira (1987) e Shikida (1996).
} 
condicional aplicada para estudar a relação entre um conjunto de características de um indivíduo e a probabilidade de que o indivíduo pertença a um entre dois grupos estabelecidos a priori.

Considere-se, por exemplo, modelar o investimento em áreas de terras. Atribuir-se-ia valor um (1) a terras e zero (0) a outro. Fatores como renda e área cultivada seriam relevantes para explicar o comportamento dos agricultores no momento do investimento.

Considerando, para exemplo, todas as variáveis exógenas representadas pelo vetor $X$, então, este vetor explica a decisão entre investir em terras ou em mercado financeiro.

$$
\begin{aligned}
\text { Prob }(Y=1)=F\left(\beta^{\prime} X\right) \rightarrow & \text { probabilidade de um indivíduo } \\
& \text { com determinadas características } \\
& X \text { investir em terras }
\end{aligned}
$$

Prob $(Y=0)=1-F\left(\beta^{\prime} X\right) \rightarrow$ probabilidade de um indivíduo com determinadas características $X$ investir num outro ativo

E a esperança de $Y$ será:

$$
E(Y)=1 . F\left(\beta^{\prime} X\right)+0 .\left[1-F\left(\beta^{\prime} X\right)\right]=F\left(\beta^{\prime} X\right)
$$

Os parâmetros $\beta$ refletem o impacto das mudanças de $X$ na probabilidade de o indivíduo investir em terras ou em outro ativo. Pode-se, por exemplo, querer saber qual é o efeito marginal da renda na probabilidade de investir em terras ou em outro ativo qualquer. Portanto, é necessário um modelo (forma-funcional) para o lado direito da equação. Assim, de acordo com GREENE (2000), se $F$ for a distribuição normal, isto é:

$$
\operatorname{Prob}(Y=1)=F\left(\beta^{\prime} X\right)=\int_{-\infty}^{\beta^{\prime} X} \phi(t) d t=\Phi\left(\beta^{\prime} X\right)
$$

Em que:

$$
\phi(t)=(2 \pi)^{-1 / 2} e^{-t^{2} / 2}
$$

Então, tem-se o modelo Probit, e se $F$ for a distribuição logística, isto é: 


$$
P(Y=1)=F\left(\beta^{\prime} X\right)=\frac{e^{\beta^{\prime} X}}{1+e^{\beta X}}=\Lambda\left(\beta^{\prime} X\right)
$$

ter-se-á o modelo Logit. A escolha de um ou outro modelo não alterará as conclusões na maioria das situações práticas. Dessa forma, optou-se por utilizar o modelo Logit para estimar a probabilidade de investimento em terras ou outro ativo financeiro qualquer, conforme (1) e (2).

Dessa forma, foi aplicada a TPD para modelar o comportamento dos potenciais investidores em terras no município de Santa Helena (PR) em 2003. De posse destes resultados pôde-se avaliar os atributos de maior relevância e o que definiu a tendência do investimento em terras pelos agricultores. A TPD foi aplicada a uma parcela da categoria de agricultores dessa região, porque essa parcela revelou-se como de grande potencial investidor.

A amostra tomada para o modelo Logit foi um total de 40 agricultores, tendo como objetivo encontrar um modelo explicativo para o comportamento da probabilidade de investimentos em área de terras $(p)$ em termos do vetor das variáveis independentes $X=\left(X_{1}, X_{2}, X_{3}, \ldots X_{K}\right)$.

A variável dependente foi definida sob duas categorias de investidores: "em terras" e "em outro". Para as variáveis independentes calculou-se um total de 10 (dez), considerando características socioeconômicas e financeiras (os diversos níveis dos atributos foram incluídos no modelo na forma de variáveis dummy), sendo:

- Finalidade do investimento - dividida em dois níveis: lucro (luc) e segurança (seg) (omitido o nível "lucro" para evitar multicolinearidade perfeita);

- Renda anual - dividida em três níveis, até $\mathrm{R} \$$ 80.000,00 (R1), de $\mathrm{R} \$ \mathbf{8 0 . 0 0 0 , 0 0}$ de $\mathrm{R} \$ 180.000,00$ (R2) e acima de $\mathrm{R} \$ 180.000,00$ (R3) (omitido o nível “até $\mathrm{R} \$ 80.000,00$ ” para evitar multicolinearidade perfeita);

- Valor do investimento - dividida em três níveis, até R\$100.000,00 (I1), de $\mathrm{R} \$ 100.000,00$ de $\mathrm{R} \$ 200.000,00$ (I2) e acima de $\mathrm{R} \$ 200.000,00$ (I3) (omitido o nível "até $\mathrm{R} \$ 100.000,00$ ” para evitar multicolinearidade perfeita);

- Condições de pagamento - dividida em dois níveis, a vista (VIS) e prazo (PRA) (omitido o nível "a vista" para evitar multicolinearidade perfeita); 
- Capital - dividida em dois níveis, próprio (PRO) e terceiros (TER) (omitido o nível "próprio" para evitar multicolinearidade perfeita);

- Credibilidade do governo - dividida em dois níveis, acredita (AL) e não acredita (BX) (omitido o nível "não acredita" para evitar multicolinearidade perfeita);

- Perfil do investidor - dividida em três níveis, conservador (C), moderado (M) e agressivo (A) (omitido o nível "moderado" para evitar multicolinearidade perfeita);

- Estado civil - dividida em três níveis, casado (CAS), solteiro (SOL) e outro (OUT) (omitido o nível "casado" para evitar multicolinearidade perfeita);

- Área cultivada - dividida em três níveis, de 30 a 80 alqueires (A1), de 80 a 140 alqueires (A2) e acima de 140 alqueires (A3) (omitido o nível “de 30 a 80 alqueires" para evitar multicolinearidade perfeita);

- Área própria - dividida em três níveis, até 30 alqueires (Aa), de 30 a 100 alqueires (Ab) e acima de 100 alqueires (Ac), (omitido o nível "até 30 alqueires" para evitar multicolinearidade perfeita);

- Escolaridade - dividida em sete níveis, primário (ES1), primeiro grau incompleto (ES2), primeiro grau completo (ES3), segundo grau incompleto (ES4), segundo grau completo (ES5), curso superior incompleto (ES6) e curso superior completo (ES7) (omitido o nível "primário" para evitar multicolinearidade perfeita e o nível "superior completo" devido a não ter nenhuma indicação).

Os softwares estatísticos utilizados no processo de análise do modelo Logit foram o Winrats versão 4.3 e Minitab versão 12.2 .

\section{Resultados e discussão}

\subsection{O potencial de investimento dos agricultores}

Santa Helena pode ser considerado um município que possui baixo número de agricultores com áreas de terra superiores a 30 alqueires, uma vez que a amostra selecionada corresponde à quase a totalidade da população. Dos agricultores entrevistados $85 \%$ estariam interessados em investir na aquisição de áreas de terras. Somente $15 \%$ dos agricultores 
entrevistados estariam dispostos a investir em outro ativo, dentre os citados os que mais apareceram foram os imóveis urbanos e aviários. No Quadro 1 está demonstrada a estratificação das 40 entrevistas realizadas, porém, é importante esclarecer que os valores expressos referem-se aos valores relativos de cada atributo avaliado individualmente.

Quadro 1 - Estratificação das entrevistas de acordo com atributos e níveis

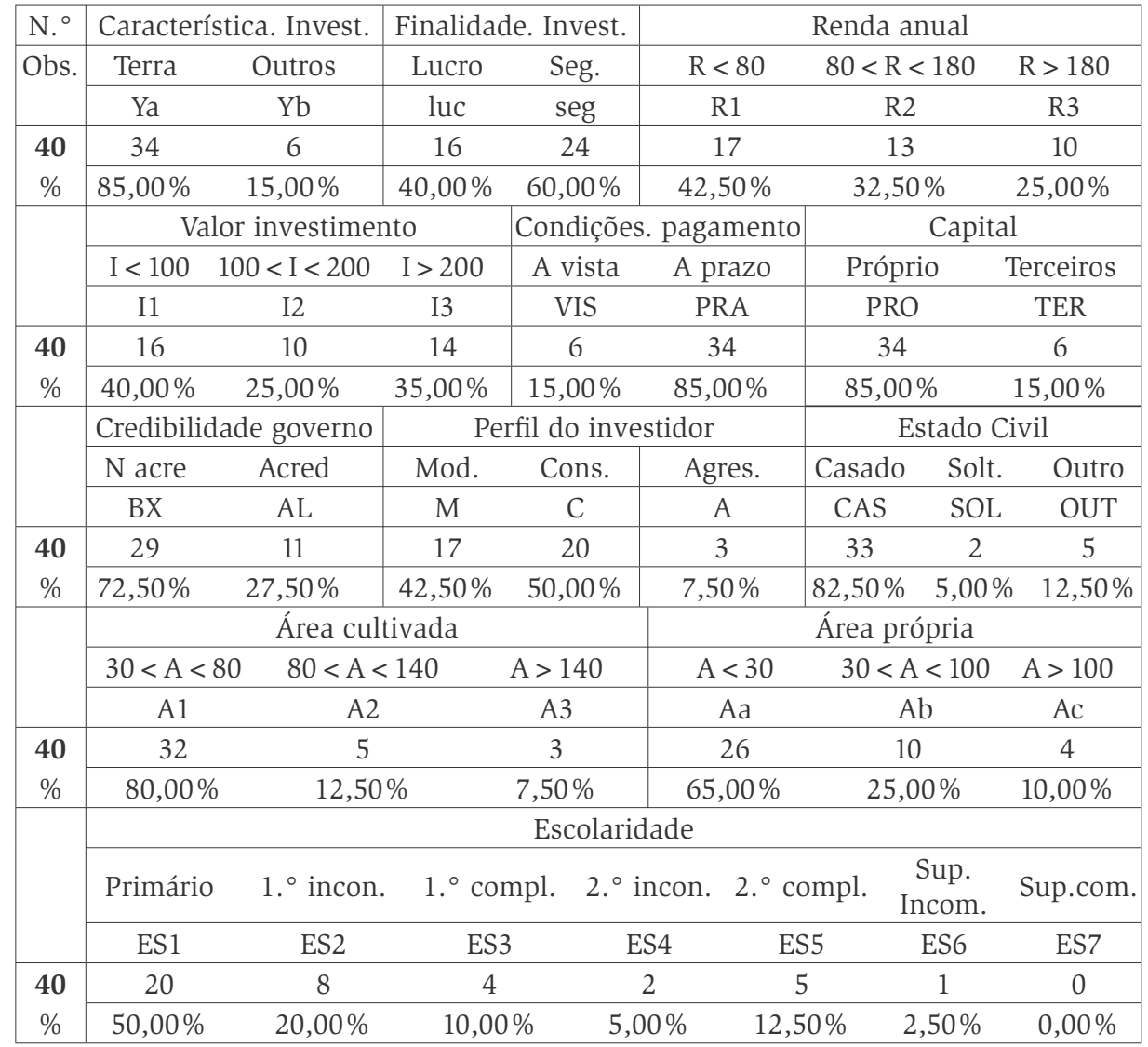

Fonte: Dados da pesquisa

Quanto à finalidade do investimento, 67,65\% dos agricultores investem em terras devido à segurança que este investimento proporciona, outros justificaram que é difícil para eles investir em outra atividade a não ser na agricultura, pois a agricultura é o nicho ao qual eles estão habituados. E 32,35\% 
dos agricultores justificaram que o objetivo do investimento em terras é primordialmente aumentar o lucro, porém a grande maioria complementou, salientando que, além das chances de aumento dos lucros o investimento em terras, também é uma forma segura de aplicar seu dinheiro (Quadro 2).

Quadro 2 - Estratificação das entrevistas em relação a variável dependente "terras" (YA)

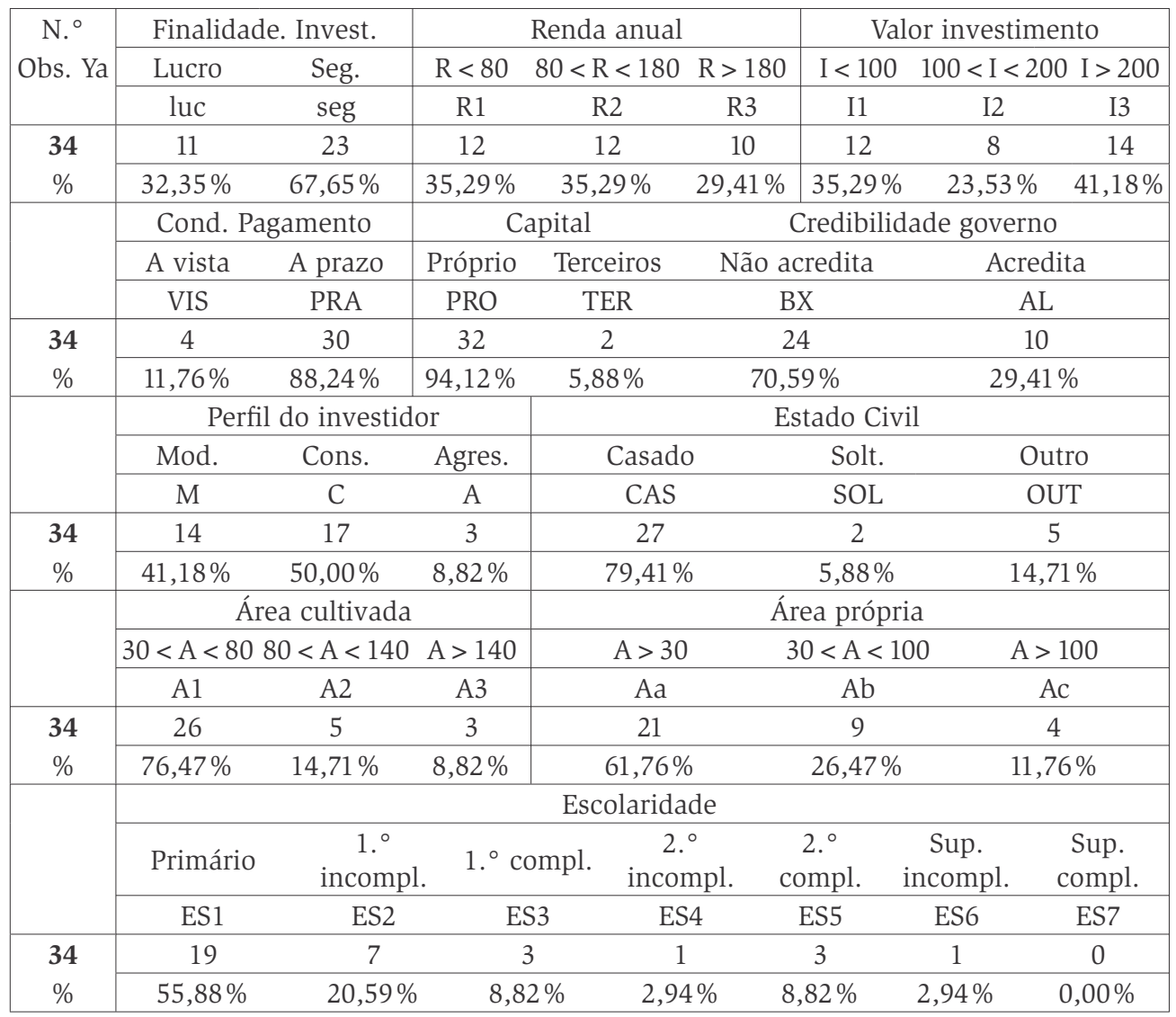

Fonte: Dados da Pesquisa

Para a estimativa da renda anual dos agricultores criou-se três faixas: “até $\mathrm{R} \$ 80.000,00$ ”, “de $\mathrm{R} \$ 80.000,00$ a $\mathrm{R} \$ 180.000,00$ ” e “superior a R\$ $180.000,00 ”$, de acordo com a área própria dos agricultores. A estratificação foi feita com base no banco de dados de bancos da região 
e escritórios de projetos agrícolas. A faixa de renda anual de até $\mathrm{R} \$$ $80.000,00$ correspondeu a $35,29 \%$ dos agricultores entrevistados, de R $\$$ $80.000,00$ a $\mathrm{R} \$ 180.000,00$ foi equivalente a $35,29 \%$ dos agricultores e $29,41 \%$ afirmaram que possuem renda anual superior a $\mathrm{R} \$ 180.000,00$. Sentiu-se uma certa resistência por parte dos agricultores quando se falava em renda (Quadro 2).

Para a variável "valor do investimento", da mesma forma que a renda, criou-se três faixas, “até $R \$ 100.000,00$ ”, “de $\mathrm{R} \$ 100.000,00$ a $\mathrm{R} \$$ $200.000,00$ ” e "acima de $\mathrm{R} \$ 200.000,00$ ” de acordo os dados dos mesmos órgãos referidos na renda. Para investimentos de até R\$100.000,00, uma fatia de $35,29 \%$ dos agricultores está disposta a investir. Para a faixa investimento de $\mathrm{R} \$ 100.000,00$ a R \$200.000,00, situam-se 23,53\% dos agricultores e $41,18 \%$ dos agricultores estariam dispostos a investir acima de $\mathrm{R} \$ 200.000,00$ (Quadro 2). Ocorreram algumas objeções a respeito do valor do investimento, principalmente no que se referia à localização do investimento, no caso da opção por terra ser confrontante ou não.

Com relação às condições de pagamento foram consideradas duas situações: pagamento à vista, ou seja, no ato da compra, e pagamento a prazo, sem especificar quanto tempo. Apenas $11,76 \%$ dos agricultores estariam dispostos a investir em terras se o pagamento fosse à vista e $88,24 \%$ dos agricultores investiriam se a forma de pagamento fosse a prazo (Quadro 2). No caso de aquisição de terras os agricultores salientaram que raramente ocorre uma compra à vista, normalmente o valor é convertido em sacas de produtos agrícolas e dividido em anos para o pagamento, coincidindo o pagamento nos meses da safra.

Para a origem do capital investido foram consideradas duas possibilidades: capital próprio e capital de terceiros. Cerca de 94,12\% dos agricultores entrevistados investiriam em terras se o capital disponível fosse próprio e apenas 5,88\% dos entrevistados investiriam com capital de terceiros (Quadro 2). Alguns entrevistados comentaram da inexistência de crédito para aquisição de terras, por isso a opção por capital próprio.

Para a variável "credibilidade no governo" trabalhou-se sempre com o governo federal atual. As opções para a credibilidade no governo são se o entrevistado "acredita" ou "não acredita". A grande maioria dos entrevistados, $72,50 \%$, acredita no governo federal e apenas $27,50 \%$ dos entrevistados não acreditam (Quadro 1). Dos entrevistados que optaram 
pela aquisição de terras 70,59\% acreditam no governo e $29,41 \%$ não acreditam (Quadro 2). Os agricultores demonstravam-se preocupados no período de transição do governo federal, mas após praticamente um ano de administração, confessam que estão mais tranqüilos quanto à estabilidade econômica e financeira do país. Alguns salientaram sobre a redução e o atraso do crédito agrícola disponível, já no primeiro ano de governo.

A respeito do perfil do investidor, perguntou-se aos agricultores em que perfil eles se enquadravam. Estabeleceram-se três níveis: "conservador", "moderado" e "agressivo". Dos agricultores entrevistados, 50\% declararam-se como sendo "conservadores", 42,50\% se designaram como sendo "moderados" e apenas 7,50\% dos agricultores declararam-se com um perfil investidor "agressivo" (Quadro 1). Dos agricultores que optaram pela opção terra, $50 \%$ declararam-se como sendo "conservadores", 41,18\% se designaram como sendo "moderados" e $8,82 \%$ dos agricultores declararam-se com um perfil investidor “agressivo” (Quadro 2). Sentiu-se uma dificuldade por parte dos agricultores em identificar a fronteira entre o perfil "conservador" e "moderado".

Estabeleceram-se três níveis para o atributo "estado civil”: casado, solteiro e outros: $82,50 \%$ dos agricultores entrevistados são casados, $5 \%$ são solteiros e 12,50\% outros (amasiados, viúvos e separados) (Quadro 1). Dos entrevistados que optaram pela opção terras, $79,41 \%$ são casados, 5,88 \% são solteiros e 14,71\% outros (Quadro 2). A grande maioria dos agricultores prefere uma relação conjugal estável.

A respeito da variável "área cultivada" estabeleceram-se três faixas, “entre 30 e 80 alqueires”, “de 80 a 140 alqueires” e "acima de 140 alqueires", conforme análise das áreas dos agricultores de Santa Helena, dados fornecidos pelos mesmos órgãos supramencionados na variável "renda anual". Observou-se que $80 \%$ dos agricultores entrevistados têm uma área cultivada entre 30 e 80 alqueires. Para a faixa de 80 a 140 alqueires tem-se uma parcela de $12,50 \%$ dos agricultores. Acima de 140 alqueires estão apenas 7,50\% dos agricultores entrevistados (Quadro 1). Dos entrevistados que optaram por terras, 76,47\% tem uma área cultivada entre 30 a 80 alqueires, $14,71 \%$ tem uma área cultivada entre 80 a 140 alqueires e $8,82 \%$ tem uma área cultivada acima de 140 alqueires (Quadro 2). O município de Santa Helena caracteriza-se por pequenas propriedades agrícolas abaixo dos 30 alqueires estabelecidos 
para pesquisa. O número de agricultores é decrescente à medida que são maiores as áreas de terra.

Para o atributo "área própria” estabeleceram-se três níveis: "até 30 alqueires", "de 30 a 100 alqueires" e "acima de 100 alqueires", conforme dados obtidos junto a órgãos supramencionados na variável "renda anual”. Para a faixa de terras de até 30 alqueires classificaram-se $65 \%$ dos entrevistados. Para a faixa de 30 a 100 alqueires estão $25 \%$ dos agricultores entrevistados. Acima dos 100 alqueires de área própria estão apenas $10 \%$ dos entrevistados (Quadro 1). Dos entrevistados que escolheram terras, $61,76 \%$ têm até 30 alqueires, 26,47\% têm entre 30 a 100 alqueires e 11,76\% têm área própria acima de 100 alqueires (Quadro 2).

Por último questionou-se a respeito da escolaridade e criaram-se sete níveis para classificação. Dos entrevistados $50 \%$ têm apenas o primário, $20 \%$ têm o primário incompleto, $10 \%$ têm o primário completo, $5 \%$ têm o segundo grau incompleto, 12,50\% têm o segundo grau completo, 2,50\% têm o superior incompleto e nenhuma ocorrência do superior completo (Quadro 1). Dos agricultores que optaram por terras 55,88\% têm apenas o primário, 20,59\% têm o primário incompleto, 8,82\% têm o primário completo, 2,94\% têm o segundo grau incompleto, 8,82\% têm o segundo grau completo, 2,94\% têm o superior incompleto e nenhuma ocorrência do superior completo (Quadro 2). Observou-se a baixa escolaridade da categoria de agricultores, pois praticamente a metade dos entrevistados tem apenas o ensino primário.

\subsection{Estimação do modelo}

Nesta etapa buscou-se aquele modelo Logit que apresenta maior eficiência segundo a análise estatística, procurando minimizar o número de variáveis no modelo com a finalidade de evitar redundâncias e poucas significâncias.

O modelo retratado na Tabela 1 não tem poder preditivo significativo. Desta forma excluímos algumas variáveis do modelo que não justificam a inclusão.

Após várias tentativas de processamento dos dados com apoio do software minitab 12.2, chegou-se a um número razoável de variáveis explicativas estatisticamente mais significativas (Tabela 2). 
Tabela 1 - Resultados da análise logit na primeira etapa

\begin{tabular}{|c|c|c|c|c|c|c|c|}
\hline Variáveis & Coef & D.P. & T-razão & P-valor & Rc & $\begin{array}{l}\text { IC de Rc } \\
\text { Linf }\end{array}$ & $\begin{array}{l}95 \% \\
\text { Lsup }\end{array}$ \\
\hline Constant & -12 & 58747 & $-0,00$ & 1,000 & & & \\
\hline Seg & 20 & 52897 & 0,00 & 1,000 & $5,32 \mathrm{E}+08$ & 0,00 & $*$ \\
\hline $\mathrm{R} 2$ & -34 & 51387 & $-0,00$ & 0,999 & 0,00 & 0,00 & $*$ \\
\hline R3 & 12 & 83616 & 0,00 & 1,000 & $1,43 E+05$ & 0,00 & $*$ \\
\hline $\mathrm{I} 2$ & 36 & 32650 & 0,00 & 0,999 & $3,70 \mathrm{E}+15$ & 0,00 & $*$ \\
\hline I3 & 26 & 44462 & 0,00 & 1,000 & $2,77 \mathrm{E}+11$ & 0,00 & $*$ \\
\hline PRA & 20 & 29810 & 0,00 & 0,999 & $4,83 E+08$ & 0,00 & $*$ \\
\hline TER & -64 & 71451 & $-0,00$ & 0,999 & 0,00 & 0,00 & $*$ \\
\hline $\mathrm{AL}$ & 13 & 57280 & 0,00 & 1,000 & $6,04 \mathrm{E}+05$ & 0,00 & $*$ \\
\hline $\mathrm{C}$ & 18 & 30532 & 0,00 & 1,000 & $7,16 \mathrm{E}+07$ & 0,00 & $*$ \\
\hline A & -31 & 708360 & $-0,00$ & 1,000 & 0,00 & 0,00 & $*$ \\
\hline SOL & 15 & 39444 & 0,00 & 1,000 & $2,72 \mathrm{E}+06$ & 0,00 & $*$ \\
\hline OUT & 44 & 62467 & 0,00 & 0,999 & $8,35 \mathrm{E}+18$ & 0,00 & $*$ \\
\hline $\mathrm{A} 2$ & -50 & 100325 & $-0,00$ & 1,000 & 0,00 & 0,00 & * \\
\hline A3 & -4 & 719963 & $-0,00$ & 1,000 & 0,03 & 0,00 & $*$ \\
\hline $\mathrm{Ab}$ & -1 & 19429 & $-0,00$ & 1,000 & 0,54 & 0,00 & $*$ \\
\hline Ac & -10 & 79583 & $-0,00$ & 1,000 & 0,00 & 0,00 & * \\
\hline ES2 & 14 & 37195 & 0,00 & 1,000 & $1,59 \mathrm{E}+06$ & 0,00 & $*$ \\
\hline ES3 & 57 & 55092 & 0,00 & 0,999 & $5,84 \mathrm{E}+24$ & 0,00 & * \\
\hline ES4 & -45 & 59054 & $-0,00$ & 0,999 & 0,00 & 0,00 & $*$ \\
\hline ES5 & -20 & 54748 & $-0,00$ & 1,000 & 0,00 & 0,00 & $*$ \\
\hline ES6 & 4 & 51797 & 0,00 & 1,000 & 39,73 & 0,00 & $*$ \\
\hline
\end{tabular}

Log-Verossimilhança $=-1,386$

Teste Qui-quadrado do modelo: $\mathrm{G}=31,044 ; \mathrm{DF}=21$; P-Valor $=0,073$

Fonte: Dados da Pesquisa

Nota: $\mathrm{DP}=$ desvio padrão; T-razão = estatística do teste de significância de Wald; p-valor = nível descritivo; Rc $=$ razão de chance e IC de Rc $95 \%$ = intervalo de $95 \%$ de confiança da razão de chance.

Com base nas variáveis da Tabela 2, aplicou-se o método de Pearson para apurar os problemas de correlação linear. As variáveis I1 e R1 apresentaram maior grau de correlação, como pode ser observado na Tabela 3. Dados estes fatos optou-se por retirar do modelo as variáveis I1 e R1. Com exceção da variável "TER" e "R1", um aumento nas outras variáveis significativas indica maior probabilidade do agricultor investir em terras (Tabela 2). 
Tabela 2 - Resultados da análise logit na segunda etapa

\begin{tabular}{lccccccc}
\hline & & & & & IC de Rc & $95 \%$ \\
Variáveis & Coef & D.P. & T-razão & P-valor & Rc & Linf & Lsup \\
\hline Constant & 0,734 & 2,160 & 0,34 & 0,734 & & & \\
seg & 1,755 & 1,582 & 1,11 & 0,267 & 5,79 & 0,26 & 128,52 \\
TER & $-3,104$ & 1,466 & $-2,12$ & 0,034 & 0,04 & 0,00 & 0,79 \\
PRA & 1,998 & 1,738 & 1,15 & 0,250 & 7,38 & 0,24 & 222,25 \\
R1 & $-1,267$ & 1,497 & $-0,85$ & 0,397 & 0,28 & 0,01 & 5,30 \\
I1 & 0,861 & 1,679 & 0,51 & 0,608 & 2,37 & 0,09 & 63,50 \\
\hline \multicolumn{7}{l}{ Log-Verossimilhança $=-9,210$} & \\
\multicolumn{7}{l}{ Teste Qui-quadrado do modelo: G $=15,397 ;$ DF $=5$; P-Value $=0,009$} \\
\hline
\end{tabular}

Fonte: Dados da Pesquisa

Nota: DP = desvio padrão; T-razão = estatística do teste de significância de Wald; p-valor = nível descritivo; Rc = razão de chance e IC de Rc $95 \%=$ intervalo de $95 \%$ de confiança da razão de chance.

Tabela 3 - Matriz de correlação linear de Pearson

\begin{tabular}{lllll}
\hline & seg & TER & PRA & R1 \\
\hline TER & $-0,372$ & & & \\
PRA & 0,086 & $-0,020$ & & \\
R1 & $-0,227$ & 0,347 & $-0,205$ & \\
I1 & $-0,271$ & 0,229 & $-0,372$ & 0,537 \\
\hline
\end{tabular}

Fonte: Dados da Pesquisa

Os atributos "renda anual" e "valor do investimento", possuem especificados três níveis, como pode ser observado no Quadro 1. Porém, no modelo apresentado na Tabela 2, está representado apenas um nível de cada atributo. Para o atributo "renda anual” apenas o nível “até R \$ 80.000,00" (R1) faz parte do modelo. Para o atributo "valor do investimento" apenas o nível “até R\$100.000,00" (I1) faz parte do modelo. A inclusão de mais um nível de cada atributo refletia na redução da significância dos atributos "renda anual" e "valor do investimento". Desta forma, para manter apenas uma variável de cada atributo seria necessário unificar as demais faixas ou refazer a questão aos entrevistados. Portanto, optou-se por excluir os atributos "renda anual" e "valor do investimento", bem como seus respec- 
tivos níveis, do modelo. Outra agravante às variáveis "R1" e "I1" é a maior correlação relativa destas variáveis, identificada pela matriz de correlação linear de Pearson, conforme demonstrado na Tabela 3.

O resultado após a exclusão dos níveis dos atributos "renda anual" e "valor do investimento", estão expressos na Tabela 4.

Tabela 4 - Resultados definitivos da análise logit

\begin{tabular}{lclllllr}
\hline & & & & & & IC de Rc & $95 \%$ \\
Variáveis & Coef & D.P. & T-razão & P-valor & Rc & Linf & \multicolumn{1}{c}{ Lsup } \\
\hline Constant & 0,582 & 1,221 & 0,48 & 0,633 & & & \\
Seg & 1,473 & 1,327 & 1,11 & 0,267 & 4,36 & 0,32 & 58,77 \\
TER & $-3,379$ & 1,380 & $-2,45$ & 0,014 & 0,03 & 0,00 & 0,51 \\
PRA & 2,034 & 1,469 & 1,38 & 0,166 & 7,64 & 0,43 & 136,16 \\
\hline
\end{tabular}

Log-Verossimilhança $=-9,210$

Teste Qui-quadrado do modelo: $\mathrm{G}=15,397 ; \mathrm{DF}=5$; P-Value $=0,009$

Fonte: Dados da Pesquisa

Nota: $\mathrm{DP}=$ desvio padrão; T-razão = estatística do teste de significância de Wald; p-valor = nível descritivo; Rc = razão de chance e IC de Rc 95\% = intervalo de $95 \%$ de confiança da razão de chance.

Pode-se observar na Tabela 4 que as variáveis "PRA" e "TER" foram consideradas as mais significativas no modelo Logit, sendo o coeficiente de correlação delas de -0,020 (Tabela 3), a qual consideramos como baixa correlação. Na Tabela 4 são apresentados os efeitos marginais e os testes da equação proposta, do modelo Logit, para investimentos em terras.

Os testes realizados para o modelo (dentre os quais destaque-se o teste de máxima verossimilhança), testam se todos os coeficientes de inclinação são zero, se foram altamente significativos, indicando que as variáveis pré-escolhidas explicam satisfatoriamente o investimento em terras.

Através da Tabela 4 podem-se verificar os seguintes resultados das variáveis que correspondem aos vários níveis dos atributos:

- O atributo finalidade do investimento, nível "segurança" (SEG) (o entrevistado define o objetivo do investimento entre "lucro e segurança"), apresenta a probabilidade de aumento de investimentos em terras de 1,473 em relação ao nível "lucro" (LUC) (variável omitida). O coeficiente "SEG" para o atributo finalidade do investimento é positivo como se esperava, uma vez que o investimento em terras com a finalidade de segurança é maior do que a finalidade lucro (o que pode 
ser confirmado com os dados do Quadro 2). Apesar do sinal correto o coeficiente não se mostrou estatisticamente significativo a $10 \%$;

- O atributo "capital", nível "terceiros" (TER) (o entrevistado define a origem dos recursos), apresenta a probabilidade de redução dos investimentos em terras de -3,379 em relação ao nível "próprio" (PRO) (variável omitida). O coeficiente "TER" para o atributo renda anual é negativo como se esperava, uma vez que o investimento em terras com capital de "terceiros" TER é menor que o nível PRO (o que pode ser confirmado com os dados do Quadro 2). Além do sinal correto o coeficiente se mostrou estatisticamente significativo a $5 \%$;

- O atributo "condições de pagamento", nível "a prazo” (PRA) (o entrevistado define as condições de pagamento desejadas), apresenta a probabilidade de aumento dos investimentos em terras de 2,034 em relação ao nível "à vista” (VIS) (variável omitida). O coeficiente "PRA" para o atributo "condições de pagamento" é positivo como se esperava, uma vez que o investimento em terras com condições de pagamento a prazo "PRA" é maior do que o nível "VIS" (o que pode ser confirmado com os dados do Quadro 2). Apesar do sinal correto o coeficiente não se mostrou estatisticamente significativo a $10 \%$.

\section{Considerações finais}

Este trabalho utilizou-se da TPD como subsídio para a identificação do comportamento dos agricultores frente a uma alternativa de investimento. A aplicação da TPD foi realizada com 40 agricultores selecionados, proprietários de imóveis rurais no município de Santa Helena - PR.

O método da TPD permitiu criar um modelo que avaliasse em conjunto os atributos da caracterização do investimento, suprindo desta forma as falhas das pesquisas mercadológicas usuais. Assim, este procedimento mostrou-se adequado na busca de informações junto ao investidor, definindo o efeito marginal relativo de cada atributo.

A restrição quanto ao número limitado de atributos não se tornou um empecilho, pois o fatorial dos atributos e seus respectivos níveis resultariam em um número bastante extenso, tornando cansativa a análise por parte do entrevistado. No entanto, a pesquisa não foi prejudicada por não terem sido agrupadas as possibilidades, pois antes de ser iniciada, explicava-se ao entrevistado o link que existia entre as questões e a importância de analisá-las de forma completa. 

de Santa Helena (PR)

A interação com os entrevistados deu-se de maneira bastante positiva, pois a TPD diverge do modo usual dos questionários. Além do mais, a segregação dos entrevistados por área própria de no mínimo 30 alqueires homogeneizou a amostra, de forma que o ambiente hipotético apresenta-se palpável aos agricultores.

A eficiência dos dados da Preferência Declarada não pode ser desprezada à medida que partindo do resultado obtido podem-se extrair diversas informações relativas à sensibilidade dos investidores e quais fatores realmente são relevantes no momento da escolha, alcançando-se resultados objetivos de natureza numérica que podem ser incluídos em modelos de tomada de decisão.

Após a aplicação da pesquisa procedeu-se uma relação simples dos dados para melhor leitura dos mesmos. Observou-se uma tendência significativa dos agricultores em investir a renda disponível em aquisições de novas áreas de terras. Pelo atributo "finalidade do investimento", percebeu-se que mais do que lucratividade os agricultores buscam segurança em seus investimentos. O atributo "condições de pagamento" caracterizou-se pela predominância de investimentos a prazo, poucos agricultores consideraram plausível a opção de investimentos com pagamento à vista. No atributo "capital", os agricultores demonstraram-se predominantemente propensos a investir utilizando basicamente capital próprio (salientaram sobre a inexistência e/ou inviabilidade de créditos para aquisição de terras ou imóveis). Segundo os agricultores, quando existe crédito os juros são abusivos.

$\mathrm{Na}$ análise do Logit, utilizaram-se a priori todas as variáveis explicativas, ou seja, todas as questões especuladas dos entrevistados foram inseridas no modelo. Percebeu-se após o primeiro processamento que os dados não eram estatisticamente significativos. Excluíram-se do modelo algumas variáveis e ocorreram alterações bruscas dos coeficientes, dos sinais dos coeficientes não coerentes e dos níveis de significância.

Portanto, para chegar ao modelo estatisticamente mais significativo foi necessário processar os dados de várias formas, para identificar as variáveis com maior grau de correlação e/ou que não eram expressivas para o modelo.

Com o modelo reestruturado mantiveram-se para a análise Logit apenas os atributos "finalidade do investimento", "capital" e "condições de pagamento", bem como seus respectivos níveis.

Os valores expressos dos coeficientes estimados mostram a consonância destes com a realidade, ou seja, com os dados fornecidos pelos agricultores 
entrevistados. Neste contexto, os agricultores que optaram pela aquisição de terras, de acordo com a análise mercadológica, mostraram-se influenciados na escolha pelo fator segurança (SEG) que a aquisição de terras proporciona em relação a outro investimento. A análise Logit comprova este fato, pois o sinal do coeficiente é positivo indicando uma relação direta com a variável dependente "terras" (Ya), apesar de não ser estatisticamente significativo a $10 \%$. Em relação à origem do capital investido, mostra-se pela pesquisa mercadológica que os agricultores não têm propensão a utilizar capital de terceiros. Da mesma forma o modelo Logit apresenta coeficiente negativo para a variável “TER”, indicando uma relação inversa com a variável dependente "terras" (Ya), sendo esta estatisticamente significativa a 5\%. Na condição de pagamento, a variável "PRA" aparece na pesquisa mercadológica como a opção mais desejada pelos agricultores. A análise Logit corrobora os dados da pesquisa mercadológica, tendo a variável "PRA" sinal do coeficiente positivo - indicando relação direta com a variável dependente "Ya", apesar de não ser estatisticamente significativa a $10 \%$.

Por fim, cumpre dizer que uma limitação deste estudo com agricultores de Santa Helena (PR) é a sua generalização. Portanto, sugere-se que mais pesquisas possam ser implementadas para examinar novas contextualizações em níveis que esta proposta não possibilitou conclusões.

\section{Referências bibliográficas}

BACHA, C. J. C. Economia e política agrícola no Brasil. São Paulo: Atlas. 2004, 226p.

BRAUN, M. B. S. Uma análise da balança comercial agrícola brasileira a guisa de sua evolução histórica recente. Informe GEPEC, Toledo, v. 8, n. 1, p. 1-21, jan./jun. 2004.

CARVALHO, M. A. de; SILVA, C. R. L. da Vulnerabilidade do comércio agrícola brasileira. Revista de Economia e Sociologia Rural, Brasília, v. 43, n. 1, p. 9-28, jan./mar. 2005.

DIAS, G. L. da S.; VIEIRA, C. A.; AMARAL, C. M. Comportamento do mercado de terras no Brasil. Serie Desarrollo Productivo. Santiago do Chile: CEPAL/Naciones Unidas, enero de 2001. 91 p.

FREITAS, A. A. F. de. Modelagem comportamental dos decisores através de técnicas de preferência declarada: uma aplicação no setor 
imobiliário de Florianópolis - SC. Florianópolis, 1995. 91 f. Dissertação (Mestrado em Engenharia de Produção) - UFSC.

GREENE, William H. Econometric analysis. 4 ed. Macmilliam Publishing Company, 2000.

HOFFMANN, R; VIEIRA. S. Análise de regressão: uma introdução à econometria. 2 ed. São Paulo: HUCITEC, 1987. 379p.

KOPITTKE, B. H.; CASAROTTO FILHO, N. Análise de investimentos. 9 ed. São Paulo: Atlas, 2000. 464 p.

KROES, E. P.; SHELDON, R. J. Stated preference methods: an introdution. Journal of Transport Economics and Policy, England: Pergamon. v. 22, n.1, p.11-25, Jan.1988.

LIZARRAGA, D. F. Modelos multivariantes de previsio del fracaso empresarial: uma aplicacion a la realidad de la informacion contable Española. Tese (Doutorado) Pamplona: Universidade de Navarra (Espanha), 1996.

MELLAGI FILHO, A; ISHIKAWA, S. Mercado financeiro e de capitais. 2 ed. São Paulo: Atlas, 2003. 384 p.

PINDYCK, R. S.; RUBINFELD, D. L. Microeconomia. São Paulo: MakronBooks, 1994. 968 p.

REYDON, B. Mercados de terras agrícolas e determinantes de seus preços no Brasil: um estudo de caso. Campinas, 1992. 322 f. Doutorado (Instituto de Economia) - UNICAMP.

SENNA, L. A. dos S.; MICHEL, F. A aceitação do pedágio por parte dos usuários gaúchos. 2000. Disponível em: < http://www.pgie.ufrgs. br/portalead/producao/www producao/disciplinas/ eng01232/artigos/ artigo3_v2.htm > . Acesso em: 08 fev. 2003.

SHIKIDA, P. F. A. Um estudo empírico do logito e probito para o bem "máquina de lavar" em cinco regiões metropolitanas do Brasil. Teoria e Evidência Econômica, Passo Fundo, v.4, n.7/8, p.37-48, mai./nov. 1996.

VICENTE, J. R. Competitividade do agronegócio brasileiro, 1997-2003. Agricultura em São Paulo, São Paulo, v. 52, n. 1, p. 5-19, jan./jun. 2005. 